\title{
Elaboración de una bebida fermentada a base de quinoa (Chenopodium quinoa)
}

\section{Production of a fermented drink based on quinoa (Chenopodium quinoa)}

\author{
Roberto Maldonado-Jibaja1, Paola Carrillo-Herrera ${ }^{1}$, Lucía Ramírez-Cárdenas², F.E. \\ Carvajal-Larenas ${ }^{2}$
}

\begin{abstract}
Resumen:
El objetivo del estudio fue elaborar una bebida fermentada a partir del extracto hidrosoluble de quinoa germinada bajo la acción de cultivos tradicionales del yogur $(S$. thermophilus y L. bulgaricus) y cultivos probióticos (Lactobacillus.acidophilus y Bifidobacterium). Se establecieron dos factores de estudio: porcentaje de goma xanthan $(0.30 \%, 0.40 \%$ y $0.50 \%$ p/p) y la relación sacarosa:fructosa $(90: 10,70: 30$, $50: 50 \mathrm{p} / \mathrm{p}$ ) añadidos en la formulación. Las variables a cuantificar fueron: acidez, $\mathrm{pH}$, viscosidad y separación de fases. El estudio se realizó bajo el diseño completamente al azar (DCA), el análisis de varianza (ANOVA) y la prueba de separación de medias Tukey con un nivel de confianza del $95 \%$. Se determinó que el mejor tratamiento incluyó en su formulación un $0.50 \%$ de goma xanthan y una relación sacarosa:fructosa de 90:10. Adicionalmente, la bebida fue de agrado de los consumidores y obtuvo 3.23 puntos en una escala hedónica de 5 puntos. Finalmente se logró una bebida fermentada de quinoa con $9 \mathrm{~g}$ de proteína por una porción de $200 \mathrm{~g}$ y con una vida útil estimada en 70 días a $4^{\circ} \mathrm{C}$. Este producto podría ser una alternativa al yogur de leche de vaca y a la bebida fermentada de soya.
\end{abstract}

Palabras clave: quinoa; bebida; fermentación.

\begin{abstract}
:
The aim of this study was to produce a drink obtained from the fermentation of the soluble extract of germinated quinoa under the action of traditional yogurt cultures ( $S$. thermophilus and L. bulgaricus) and probiotic cultures (Lactobacillus. acidophilus and Bifidobacterium ). Two factors under study were established: the xanthan gum percentage $(0.30 \%, 0.40 \%$ and $0.50 \% \mathrm{w} / \mathrm{w})$ and sucrose:fructose relation $(90: 10$, $70: 30,50: 50)$ added in the formulation. The quantified variables were: acidity, $\mathrm{pH}$, viscosity and phase separation. The study was conducted under the completely randomized design (CRD), analysis of variance (ANOVA) and Tukey mean separation test with a confidence level of $95 \%$. The best treatment included $0.50 \%$ xanthan gum and sucrose:fructose relation of 90:10 in its formulation. The product was subjected to sensory tests in which it was determined that the product liked to consumers (score of 3.2 points on a 5-point hedonic scale). Finally, a fermented drink made from quinoa was obtained with $9 \mathrm{~g}$ of protein per $200 \mathrm{~g}$ of product and with a shelf life estimated in 70 days at $4{ }^{\circ} \mathrm{C}$. This product could be an alternative to fermented beverages such as cow's milk yogurt and soy-fermented drink.
\end{abstract}

Keywords: quinoa; beverage; fermentation.

\footnotetext{
1 Universidad San Francisco de Quito, Quito, Ecuador \{roberto.maldonado, paola.carrillo\} @estud.usfq.edu.ec

2 Universidad San Francisco de Quito, Quito, Ecuador \{lramirez, fcarvajal\} @usfq.edu.ec
} 


\section{Introducción}

Alrededor del mundo se han desarrollado productos a partir de extractos vegetales como soya, maní y sésamo; principalmente bebidas y precipitados proteicos (Stanbury y otros, 1995; Sicherer, 2000). A pesar de esto, los productos sustitutos con base vegetal presentan una baja aceptación debido a su sabor (Nnam, 2003). Por ende, se ha optado por la fermentación para desarrollar sabores más agradables y mejorar las propiedades reológicas con el fin de aumentar la aceptabilidad (Chan y Beuchat, 1992). Adicionalmente, la fermentación consigue disminuir y en varios casos eliminar los factores antinutricionales que restan calidad nutricional a los alimentos con base vegetal (Reddy \& Pierson, 1994).

En la actualidad, la soya y sus derivados se constituyen como la principal opción vegetal en el mercado por su versatilidad y sus características nutricionales. Sin embargo, el $0.4 \%$ de la población infantil presenta alergia a los productos que contienen esta leguminosa (Bock, 1987). En consecuencia, se han empezado a usar extractos vegetales diferentes a la soya, entre ellos, recientemente, la quinoa (Chenopodium quinoa), que ha hecho su aparición en el mercado internacional y ecuatoriano; una de sus cualidades es su contenido proteico entre 13.8 y $21.9 \%$ según la variedad usada (Rojas y otros, 2006). Este pseudocereal se comercializa actualmente en productos procesados como fideos de pasta corta, sopa instantánea, bebidas malteadas, expandidos y tempeh (Mazón y otros, 2009).

El valor nutricional de la quinoa es superior al de la soya y demás alimentos tradicionales con base vegetal. Esto se debe principalmente a que la composición de aminoácidos del seudocereal está considerada muy cercana a la ideal (FAO/WHO, 2013). Es así, que su calidad nutricional en cuanto a proteínas rivaliza incluso con las encontradas en la leche (Maldonado, 2010; Rojas y otros, 2010).

Entre las fracciones proteicas principales de la quinoa se encuentran las albúminas y globulinas conocidas por su elevada calidad proteica (Ishimoto \& Monteiro, 2010). Sin embargo, estas presentan factores antinutricionales como inhibidores de proteasas y lectinas, que tienen un efecto negativo en la digestibilidad y disponibilidad de los aminoácidos (Vega-Gálvez, y otros, 2010). Por consiguiente, es necesario un método para eliminar o reducir estos componentes. Está demostrado que la fermentación con diferentes especies de bacterias y hongos reduce o elimina los factores antinutricionales y componentes tóxicos de los alimentos con base vegetal (Reddy \& Pierson, 1994).

Añadido a los beneficios antes mencionados, cabe destacar que, si se usan cultivos probióticos para la fermentación, estos traerán efectos beneficiosos a quien los consuma (Schrezenmeir \& Vrese, 2001; Brown \& Valiere, 2004). El término probiótico se refiere a la preparación de un producto alimenticio con microorganismos definidos (principalmente Lactobacilos y Bifidobacterias) en cantidades suficientes, de tal manera que tengan un efecto sobre la flora intestinal del consumidor. Está demostrado que el consumo de cultivos probióticos inhibe el crecimiento de bacterias negativas para el organismo como Clostridium difficile, ayuda a normalizar la función digestiva, regenera la flora intestinal y refuerza el sistema inmunológico, más aún si el consumo de probióticos está acompañado de una dieta adecuada y ejercicio físico regular (Gill y Prasad, 2008; Gorbach, 2000).

El aporte de la quinoa en cuanto a calidad nutricional es importante; sin embargo y contradictoriamente, no existe un producto que aproveche estas características y las combine con aquellas ventajas que se obtienen mediante la fermentación en un producto líquido. Esta situación se podría explicar, en parte, por la dificultad que representa el desarrollo de acidez en extractos vegetales a través de la fermentación.

Existe evidencia que los extractos vegetales por sí solos no cumplen los requerimientos físico-químicos necesarios para el desarrollo de bacterias como las encontradas en el yogur. Esta limitación tiene origen en la concentración de azúcares y/o fuentes de nitrógeno presentes en los extractos vegetales, que por lo general es baja e insuficiente para el desarrollo de bacterias como las del yogur. Por ejemplo, se ha demostrado que $L$. bulgaricus no puede crecer en el extracto hidrosoluble de soya a menos 
que se adicionen azúcares como la fructosa; aun así, algunos investigadores han reportado la incapacidad de los cultivos tradicionales del yogur para producir ácido láctico (Beuchat y Nail, 1978). Sin embargo, es un obstáculo que se puede superar con el empleo de aditivos que permitan crear condiciones adecuadas para la fermentación (Martensson y otros, 2001).

Se han estudiado varios sustratos para el desarrollo de acidez en extractos vegetales, en especial azúcares; los más sobresalientes son: la sacarosa, la glucosa, la fructosa y la lactosa. A más de ello, estudios previos realizados en extracto hidrosoluble de maní muestran que el desarrollo de bacterias ácido lácticas también depende del tipo de cepa (Bucker y otros, 1979). Por lo que además de la adición de azúcares (sacarosa y fructosa), se requiere el uso de bacterias ácido lácticas diferentes a las empleadas en el yogur tradicional (Martensson y otros, 2001).

Finalmente, es conocido que los productos obtenidos a partir de los extractos vegetales presentan una gran inestabilidad y una subsecuente separación de fases y precipitación (Bucker y otros, 1979). Sin embargo, este obstáculo puede ser superado mediante espesantes y estabilizantes.

Es por ello que el objetivo del estudio fue desarrollar una bebida fermentada que se asemeje al yogur en sabor y textura, obtenida a partir del extracto hidrosoluble de quinoa bajo la acción de cultivos acidófilos (Streptococcus thermophilus, Lactobacillus bulgaricus) y cultivos probióticos (Bifidibacterium lactis, Lactobacillus acidophilus).

\section{Materiales y métodos}

\subsection{Materia prima}

Se empleó quinoa germinada (Chenopodium quinoa variedad tunkahuan) adquirida del proveedor local (Supermaxi - Corporación La Favorita C.A, Ecuador), cultivo acidófilo (YO-FAST 88) compuesto de los microorganismos: Streptococcus thermophilus, Lactobacillus delbrueckii subsp. bulgaricus. Lactobacillus acidophilus y Bifidobacterium; estabilizante (CCM-725) compuesto de almidón modificado, carragenina y pectina adquiridos en Descalzi S.A. Quito, Ecuador. Goma xanthan, sacarosa, fructosa, sorbato de potasio, bicarbonato de sodio (La casa del Químico, Quito, Ecuador), agua potable y pulpa de maracuyá adquiridos de proveedor local (Supermaxi - Corporación La Favorita C.A, Ecuador).

\subsection{Preparación del extracto de quinoa}

A partir de $1000 \mathrm{~g}$ de quinoa se requirieron 2 litros de agua para el remojo, 4 litros de agua más $1 \mathrm{~g}$ de bicarbonato para la cocción y 5 litros para el licuado, para obtener aproximadamente $4000 \mathrm{~g}$ de extracto hidrosoluble. El procedimiento se detalla en la Figura 1.

\subsection{Preparación de la bebida fermentada}

A $100 \mathrm{~g}$ de extracto hidrosoluble de quinoa se adicionaron $0.02 \mathrm{~g}$ de cultivo acidófilo, $0.10 \mathrm{~g}$ de estabilizante y $0.01 \mathrm{~g}$ de sorbato de potasio. Para el factor en estudio goma de xanthan, se empleó $0.30 \%, 0.40 \%$ y $0.50 \%$. Para el caso de la relación sacarosa:fructosa se fijaron $3 \mathrm{~g}$ en proporciones 90:10, 70:30 y 50:50 respectivamente. Los valores de ambos factores se establecieron a base de la información bibliográfica (Almendáriz y Bolaños, 2012; Matersson y otros, 2001) y pruebas preliminares. El procedimiento de preparación se detalla en la Figura 1. 


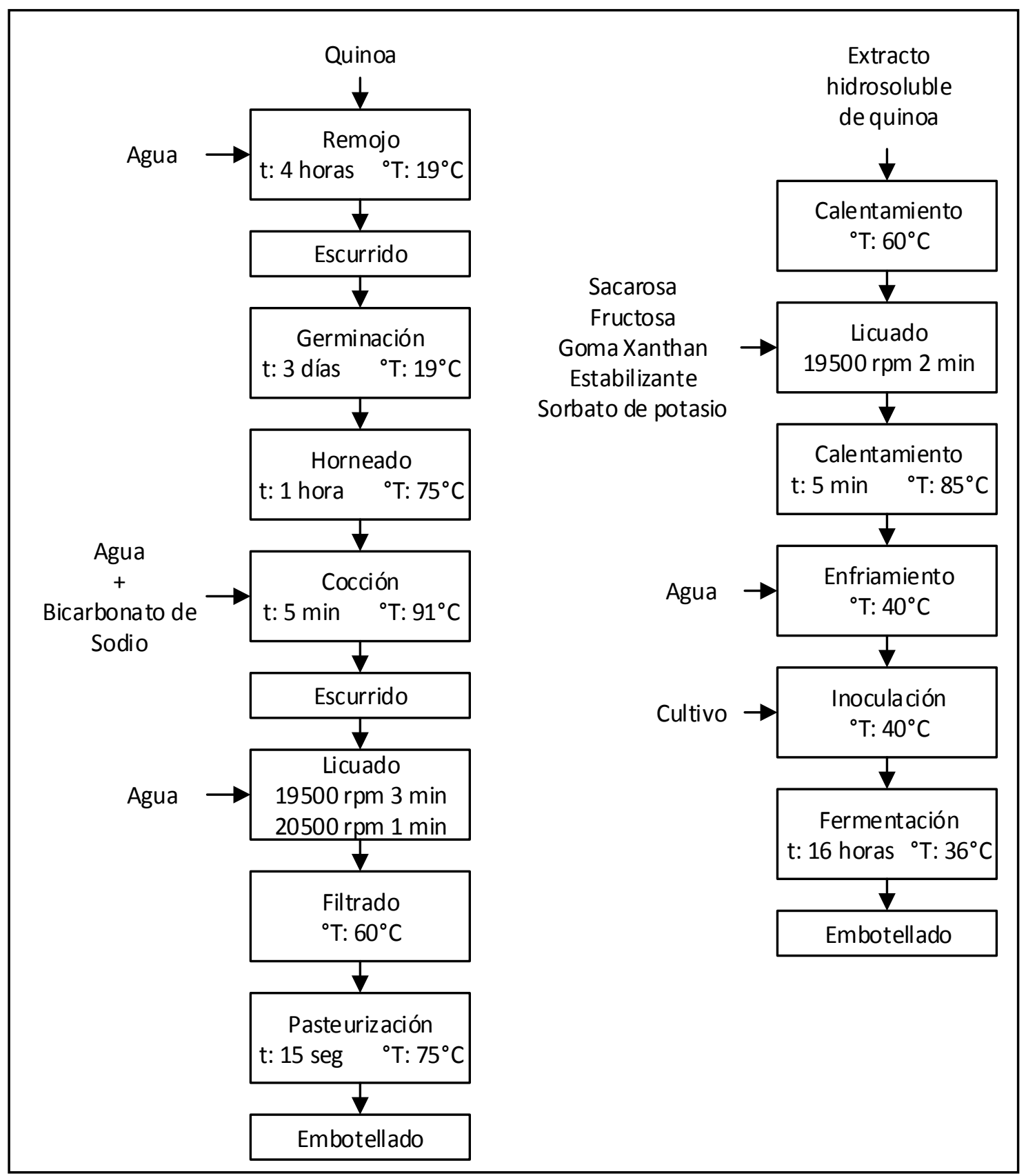

Figura 1. Proceso de preparación del extracto y bebida fermentada de quinoa.

\subsection{Diseño experimental}

El estudio se realizó mediante el diseño completamente al azar con un arreglo factorial $3^{2}$ con tres repeticiones. La goma xanthan y la relación sacarosa:fructosa son los factores bajo estudio.

\subsection{Variables de respuesta}

\subsubsection{Separación de fases}

El método aplicado se desarrolló a base de pruebas preliminares y bibliografía disponible (Guinee y otros, 2000). Se tomaron $11 \mathrm{~mL}$ de bebida fermentada a $12^{\circ} \mathrm{C}$ y se sometió la muestra a centrifugación (centrífuga Centra GP8F, rotor 210) a 2252 gravedades 
por dos horas. Al finalizar, se midieron los $\mathrm{mL}$ de sobrenadante (calibrador digital Truper CALDI-6MP $\pm 1 \mathrm{~mm})$. Se empleó la Ecuación 1.

$$
\% \text { Separación de fases }=\frac{\mathrm{mm} \text { del sobrenadante }}{\mathrm{mm} \text { totales de la muestra }} * 100
$$

\subsubsection{Acidez}

Se aplicó el método descrito en la norma NTE INEN 2395:2011.

\subsection{3. $\mathrm{pH}$}

Se aplicó el método descrito en la norma NTE INEN 325.2002.

\subsubsection{Viscosidad}

Mediante el uso de un viscosímetro (Brookfield Digital Viscosieter Modelo DV II RV spinle 02 y $20 \mathrm{rpm}$ ) se analizaron las muestras bajo los siguientes parámetros establecidos en pruebas preliminares: temperatura de $20^{\circ} \mathrm{C}$ con un tiempo de 5 minutos para estabilizar la lectura. Los datos se promediaron y expresaron en centipoise (cP).

\subsection{Análisis estadístico}

Se aplicó el análisis de varianza (ANOVA) y la prueba de Tukey $(\alpha=0.05)$. Para el análisis de la variable separación de fases, se transformaron los datos a escala logarítmica (Sánchez, 2012) debido a la gran diferencia entre los datos obtenidos de los tratamientos con $0.3 \%$ de goma en comparación con $0.4 \%$ y $0.5 \%$.

\subsection{Ponderación de las variables}

Con el fin de determinar el mejor tratamiento, se designó el valor de 4 a la variable más importante seguida de una calificación de 3, 2 y 1 para las respectivas variables siguientes. Debido a la seguridad microbiológica se asignó como atributo más importante al $\mathrm{pH}(<4.5)$, seguido de la viscosidad como atributo deseable en el producto (>1000 cP) establecido a base de la bibliografía (Almendáriz y Bolaños, 2012). Luego, se designó a la separación de fases $(<1 \%)$ al ser un problema frecuente en bebidas fermentadas (Bucker y otros, 1979) seguida de la acidez $(\geq 0.3 \%)$ debido a que este factor puede ser corregido fácilmente luego de la fermentación.

\subsection{Otros aspectos}

Estudio de vida útil: se aplicó el modelo de degradación cinética y la ecuación de Arrhenius. Las muestras fueron almacenadas a $4^{\circ} \mathrm{C}, 19^{\circ} \mathrm{C}$, y $35^{\circ} \mathrm{C}$. Se determinó la acidez (\% ácido láctico) como indicador de deterioro.

Cuantificación de cultivo añadido: se realizó la cuantificación de bacterias ácido lácticas ( $\mathrm{LAB}$ ) en placas petrifilm, el resultado fue contrastado con el valor de referencia en la norma NTE INEN 2395:2011 de 107 UFC/g (suma de microorganismos que comprenden el cultivo definido para cada producto: yogur).

Análisis proteico: se siguió el protocolo AOAC 955.04D al aplicar el método Kjeldahl.

Evaluación Sensorial: se saborizó a la bebida fermentada con pulpa de maracuyá ( $\mathrm{v} / \mathrm{v} 20 \%$ ) y sacarosa (p/v $7 \%$ ). Se realizó una prueba de nivel de agrado a 62 jueces consumidores (Witting, 2001) (15-35 años, 28 mujeres, 40 hombres). Cada juez recibió 50 $\mathrm{mL}$ de la muestra a $4^{\circ} \mathrm{C} \pm 1^{\circ} \mathrm{C}$. Se aplicó una escala hedónica de 5 puntos y se calculó la media de la sumatoria de las calificaciones para el análisis de datos. 


\section{Resultados y discusión}

El análisis de los resultados (Tabla 1 y Tabla 2) demostró que existió diferencia significativa entre los tratamientos, un efecto significativo del factor A (relación sacarosa:fructosa) para las variables: acidez, $\mathrm{pH}$ y viscosidad; del factor $\mathrm{B}$ (porcentaje de goma xanthan) para todas las variables bajo estudio, así como de la interacción de ambos factores.

Tabla 1. Resumen de los resultados del ANOVA para todas las variables de respuesta

\begin{tabular}{|l|l|l|l|l|l|}
\hline \multirow{2}{*}{ Fuente de Variación } & \multicolumn{4}{|c|}{ Fc-Variables de Respuesta } & \\
\cline { 2 - 6 } & $\begin{array}{l}\text { Acidez } \\
\text { (\%Ácido } \\
\text { Láctico) }\end{array}$ & $\mathbf{p H}$ & $\begin{array}{l}\text { Viscosidad } \\
\text { (cP) }\end{array}$ & $\begin{array}{l}\text { Separación } \\
\text { de Fases } \\
(\%)\end{array}$ & Ft (a=0.05) \\
\hline Tratamientos & $20.97^{*}$ & $83.52^{*}$ & $1675.58^{*}$ & $1871.72^{*}$ & 2.51 \\
\hline A: sacarosa:fructosa & $51.14^{*}$ & $150.39^{*}$ & $220.62^{*}$ & 3.01 & 3.55 \\
\hline B: Goma xanthan & $9.14^{*}$ & $10.18^{*}$ & $5617.02^{*}$ & $7476.73^{*}$ & 3.55 \\
\hline AXB & $11.80^{*}$ & $86.74^{*}$ & $432.34^{*}$ & $3.57^{*}$ & 2.93 \\
\hline $\begin{array}{l}\text { Coeficiente } \\
\text { Variación (\%) }\end{array}$ & 1.46 & 0.12 & 0.58 & 2.72 & - \\
\hline
\end{tabular}

${ }^{*} \mathrm{p}<0.05$

Tabla 2. Resumen de los resultados de cada variable de respuesta y cada tratamiento

\begin{tabular}{|l|l|l|l|l|l|l|}
\hline \multirow{2}{*}{$\begin{array}{l}\text { Trata- } \\
\text { miento }\end{array}$} & \multirow{2}{*}{$\begin{array}{l}\text { Factor } \\
\mathbf{A}^{*}\end{array}$} & $\begin{array}{l}\text { Factor } \\
\mathbf{B}^{* \star}\end{array}$ & $\begin{array}{l}\text { Acidez } \\
\text { (\% de ácido } \\
\text { láctico) }\end{array}$ & $\mathbf{p H}$ & $\begin{array}{l}\text { Viscosidad (cP) } \\
\text { Separación } \\
\text { de fases (\%) }\end{array}$ \\
\hline 1 & $90: 10$ & 0.3 & $\begin{array}{l}0.28 \\
0.00^{\mathrm{a}(1)}\end{array}$ & $3.55 \pm 0.01^{\mathrm{f}}$ & $550.00 \pm 0.00^{\mathrm{f}}$ & $56.24 \pm 2.46^{\mathrm{a}}$ \\
\hline 2 & $90: 10$ & 0.4 & $0.26 \pm 0.01^{\mathrm{bc}}$ & $3.69 \pm 0.01^{\mathrm{b}}$ & $756.67 \pm 2.89^{\mathrm{e}}$ & $1.42 \pm 0.38^{\mathrm{b}}$ \\
\hline 3 & $90: 10$ & 0.5 & $0.30 \pm 0.03^{\mathrm{a}}$ & $3.56 \pm 0.02^{\mathrm{ef}}$ & $1240.00 \pm 34.64^{\mathrm{b}}$ & $0.89 \pm 0.17^{\mathrm{cd}}$ \\
\hline 4 & $70: 30$ & 0.3 & $0.26 \pm 0.01^{\mathrm{bcd}}$ & $3.73 \pm 0.02^{\mathrm{a}}$ & $556.67 \pm 2.89^{f}$ & $56.87 \pm 1.68^{\mathrm{a}}$ \\
\hline 5 & $70: 30$ & 0.4 & $0.23 \pm 0.01^{\mathrm{de}}$ & $3.63 \pm 0.01^{\mathrm{cd}}$ & $766.67 \pm 5.77^{\mathrm{de}}$ & $0.90 \pm 0.08^{\mathrm{cd}}$ \\
\hline 6 & $70: 30$ & 0.5 & $0.20 \pm 0.01^{\mathrm{e}}$ & $3.75 \pm 0.01^{\mathrm{a}}$ & $903.33 \pm 2.89^{\mathrm{c}}$ & $0.88 \pm 0.11^{\mathrm{d}}$ \\
\hline 7 & $50: 50$ & 0.3 & $0.26 \pm 0.01^{\mathrm{bcd}}$ & $3.60 \pm 0.01^{\mathrm{de}}$ & $420.67 \pm 3.06^{\mathrm{g}}$ & $56.50 \pm 0.65^{\mathrm{a}}$ \\
\hline 8 & $50: 50$ & 0.4 & $0.24 \pm 0.01^{\mathrm{cd}}$ & $3.65 \pm 0.01^{\mathrm{bc}}$ & $798.33 \pm 5.77^{\mathrm{d}}$ & $1.28 \pm 0.09^{\mathrm{b}}$ \\
\hline 9 & $50: 50$ & 0.5 & $0.25 \pm 0.01^{\mathrm{bcd}}$ & $3.62 \pm 0.02^{\mathrm{cd}}$ & $1370.00 \pm 17.32^{\mathrm{a}}$ & $0.83 \pm 0.02^{\mathrm{d}}$ \\
\hline
\end{tabular}

${ }^{1}$ Los superíndices indican los resultados de la prueba de Tuckey, $\mathrm{p}<0.05$

*Factor A: relación sacarosa:fructosa

${ }^{* *}$ Factor B: porcentaje de goma xanthan

\subsection{Acidez y pH}

El mayor efecto se observó en la relación sacarosa: fructosa (factor A), al ser la acidez producto de la fermentación de los azúcares disponibles en el extracto (Afaneh y otros, 2011; Dong y otros, 2005; lancu y otros, 2010). La acidez de los tratamientos 1, 2, y 3 fue superior a la de los tratamientos 7, 8 y 9 ( Tabla 2) a pesar que se esperaba lo contrario ya que estos últimos al tener mayor cantidad de fructosa podían ser mayormente fermentados por L. bulgaricus (Jiménez y otros, 2003). Esto posiblemente se debe a que el $S$. thermophilus al tener la habilidad de descomponer la sacarosa en glucosa y fructosa por su actividad invertasa (Courtin y Rul, 2003) pudo contribuir a que L. bulgaricus actúe sin necesidad de mayores cantidades de fructosa en la formulación. Adicionalmente, el proceso de germinación de la quinoa eleva el contenido de azúcares reductores debido al fraccionamiento de carbohidratos. Por ejemplo, el almidón en glucosa o maltosa (Álvarez \& Cecilia, 2013). Dichos azúcares, junto con la sacarosa, son fermentados por $L$. acidophilus (Kullen, y Klaenhammer, 1999), contribuyendo al incremento de la acidez sin la necesidad de adicionar fructosa. 
A su vez, la acidez del producto es el resultado del nivel de concentración del extracto líquido. En este caso al emplearse una relación de agua:quinoa de 5:1 se reduce la concentración de sustratos disponibles, lo cual ocasiona la dilución del ácido formado. Es así como en un estudio de una bebida fermentada obtenida a partir de maíz dulce se encontró que una relación de agua:maíz de 2:1 resultó en un producto con 1.1\% de acidez (Supavititpatana y otros, 2010). En otro estudio se encontró que una bebida fermentada de soya con una relación de agua:soya de $4: 1$ alcanzó un nivel de acidez del $0.47 \%$, mientras que otras bebidas más diluidas alcanzaron valores menores al 0.38 \% (Quicazán y otros, 2001).

Respecto al otro factor, porcentaje de goma xanthan, el efecto significativo se explica por la acción de Bifidobacterium. Así, se ha encontrado que estas bacterias podrían fermentar los polisacáridos naturales, entre ellos la goma xanthan (Bolado y Acedo, 2006).

Todos los tratamientos presentaron un $\mathrm{pH}$ dentro de los rangos reportados para productos fermentados tales como el yogur común (Luquet, 1993) y bebidas vegetales fermentadas ( $\mathrm{pH}$ <4.50) (Opara, y otros, 2013) (Tabla 2). Al existir una relación entre pH y acidez, los resultados obtenidos en $\mathrm{pH}$ se podrían explicar parcialmente con los argumentos previamente mencionados en acidez. Sin embargo, para la variación de pH existen otros factores a considerar. Se conoce que los alimentos de procedencia animal poseen una alta capacidad amortiguadora (que ayuda a mantener un $\mathrm{pH}$ estable) mientras que los alimentos de procedencia vegetal no. Así, en una bebida fermentada de soya-maíz se alcanzó una acidez del 0.06\% mientras que el pH disminuyó a 4.00-4.50 (Moses, 2012).

\subsection{Separación de fases y viscosidad}

Los tratamientos con $0.40 \% 00.50 \%$ de goma xanthan presentaron mayor estabilidad (Tabla 2). Estos tratamientos fueron centrifugados por 6 horas adicionales al tiempo estándar del método ( 2 horas) y no hubo cambios cuantificables en este parámetro.

Los resultados se explicarían debido a la interacción de la goma xanthan junto con el almidón (presente en el estabilizante) ya que su acción conjunta resulta más eficaz que al ser empleados individualmente (Torres, 2011). Asimismo, la quinoa empleada para la elaboración del extracto líquido también presentaría un aporte propio de almidón que a la vez sirve como espesante y estabilizante natural (Torres, 2011; Álvarez \& Cecilia, 2013).

Si bien la mayor separación de fases se observó en los tratamientos con $0.3 \%$ de goma xanthan, el producto al ser almacenado a $4^{\circ} \mathrm{C}$ por un período de un mes no presentó separación, por lo que incluso este porcentaje sería suficiente para la estabilidad.

En cuanto a la viscosidad, el mayor efecto sobre este parámetro lo generó la adición de goma xanthan (factor B) ya que los niveles de goma xanthan empleados afectaron significativamente las características reológicas del producto. De esta manera, se constata lo demostrado en estudios anteriores, que existe una relación directamente proporcional entre el incremento de la cantidad de goma xanthan y la viscosidad (Torres, 2011). Por consiguiente, se obtuvo un incremento en la viscosidad de los tratamientos 3, 6 y 9 (con $0,50 \%$ ). Estos resultados son similares a los obtenidos en bebidas fermentadas similares de soya, lupino y de avena (Martensson y otros, 2002).

El efecto del factor A podría explicarse por la formación de exopolisacáridos. El cultivo Yo-Fast 88 usado para la fermentación contiene L. delbrueckii ssp bulgaricus cepa conocida por su capacidad de sintetizar exopolisacáridos en medios ricos en glucosa (Martenssony otros, 2000). Si bien no hay glucosa directamente disponible, la acción sinergística de $S$. thermophilus desdoblaría la sacarosa en glucosa y fructosa (Courtin y Rul, 2003) y contribuiría a la síntesis de exopolisacáridos que aumentan la viscosidad. 


\subsection{Ponderación}

La ponderación de las variables (Tabla 3) dio como resultado la elección del tratamiento 3 como el mejor. Si bien el tratamiento 9 es muy cercano al tratamiento 3 , no se eligió al mismo ya que este contenía una mayor cantidad de fructosa y por ende representaba incrementos en sus costos de elaboración, además que los resultados del diseño experimental demostraron que no es estrictamente necesaria la adición de este azúcar.

Tabla 3. Ponderación de los tratamientos.

\begin{tabular}{|l|l|l|l|l|l|}
\hline Tratamiento & $\begin{array}{l}\mathbf{p H} \\
<\mathbf{4 . 5}\end{array}$ & $\begin{array}{l}\text { Viscosidad } \\
\mathbf{\mathbf { 1 0 0 0 } c \mathbf { P }}\end{array}$ & $\begin{array}{l}\text { Separación de fases } \\
<\mathbf{1 \%}\end{array}$ & $\begin{array}{l}\text { Acidez } \\
\mathbf{2 0 . 3} \%\end{array}$ & Total \\
\hline 1 & 4 & 0 & 0 & 1 & 5 \\
\hline 2 & 4 & 0 & 0 & 0 & 4 \\
\hline 3 & 4 & 3 & 2 & 1 & $10^{*}$ \\
\hline 4 & 4 & 0 & 0 & 0 & 4 \\
\hline 5 & 4 & 0 & 2 & 0 & 6 \\
\hline 6 & 4 & 0 & 2 & 0 & 6 \\
\hline 7 & 4 & 0 & 0 & 0 & 4 \\
\hline 8 & 4 & 0 & 0 & 0 & 4 \\
\hline 9 & 4 & 3 & 2 & 0 & 9 \\
\hline
\end{tabular}

*Tratamiento con mayor puntaje

\subsection{Otros aspectos}

La evaluación sensorial del tratamiento tres dio como resultado una media de 3.23 puntos en la escala hedónica de 5 puntos (Tabla 4). El resultado de esta media se ubica en la escala hedónica (Tabla 3) entre las opciones: "Me gustaría y tomaría de vez en cuando" y "Tomaría si estuviera disponible pero no me esforzaría para esto".

Tabla 4. Características finales de la bebida fermentada

\begin{tabular}{|l|l|}
\hline Característica & Resultado \\
\hline Acidez (\% de ácido láctico) & $0.30 \%$ \\
\hline Ph & 3.56 \\
\hline Viscosidad (cP) & $1240.00 \mathrm{Cp}$ \\
\hline Separación de Fases (\%) & $0.89 \%$ \\
\hline Proteína (g/200g) & $9 \mathrm{~g}$ \\
\hline $\begin{array}{l}\text { Suma de microorganismos que comprenden el cultivo definido para cada } \\
\text { producto: yogur (UFC/g)* }\end{array}$ & $1 \times 10^{8} \mathrm{UFC} / \mathrm{g}$ \\
\hline Vida útil a $4^{\circ} \mathrm{C}($ días) & 70 días \\
\hline Nivel de agrado** (escala hedónica de 5 puntos) & $3.23 / 5$ puntos \\
\hline
\end{tabular}

${ }^{*}$ Realizado al final de la vida útil ( $\geq 10^{7}$ acorde con la Norma NTE INEN 2395:2011)

${ }^{*}$ De la bebida fermentada saborizada a base de intención de compra

El conteo de microorganismos cumplió con lo establecido por la norma NTE INEN (Tabla 4). El análisis de proteínas resultó en un contenido de $9 \mathrm{~g} / 200 \mathrm{~g}$ comparable con los yogures comerciales. El tiempo de vida útil determinado fue 75 días a $4^{\circ} \mathrm{C}$, pero con el fin de brindar un margen de seguridad se reporta la vida útil como 70 días para una temperatura de almacenamiento de $4^{\circ} \mathrm{C}$. 


\section{Conclusiones y recomendaciones}

Se elaboró una bebida fermentada mediante extracto hidrosoluble bajo la acción de cultivos acidófilos, con un nivel de aceptabilidad de $3.25 / 5$ evaluado en jueces consumidores. Se determinó el procedimiento y la mejor formulación para obtener una bebida fermentada a base de quinoa, al ser esta la del tratamiento 3 (90:10 sacarosa:fructosa y $0.5 \%$ de goma xanthan $\mathrm{p} / \mathrm{p}$ ). La formulación final incluye extracto líquido de quinoa, cultivo acidófilo, sacarosa, goma xanthan, estabilizante, sorbato de potasio, pulpa de maracuyá y sacarosa. El producto alcanzó un tiempo de vida útil estimado de 70 días a $4{ }^{\circ} \mathrm{C}$ en donde los cultivos acidófilos son viables y bajo la Norma INEN. EI producto obtenido tiene un potencial nutricional importante, pues una porción de $200 \mathrm{~g}$ de bebida fermentada de quinoa aportaría, $9 \mathrm{~g}$ de proteínas.

Se recomienda realizar el estudio con niveles superiores a $0.5 \%$ de goma xanthan para observar los cambios en la viscosidad del producto en caso que se desee obtener una bebida fermentada de características más espesas, ya que la bebida obtenida presenta características de yogur bebible. También se recomienda adicionar en la formulación del producto otros tipos de azúcares por ejemplo glucosa para observar su efecto sobre la acidez final. A la par, variar las relaciones de agua:quinoa para incrementar la concentración de nutrientes disponibles para los cultivos acidófilos.

Finalmente, estudiar otras opciones para mejorar el sabor del producto, como incluir la adición de pulpas de otras frutas y saborizantes artificiales.

\section{Bibliografía}

Afaneh, I., Abu-Alruz, K., Quasem, J., Sundookah, A., Abbadi, J., Alloussi, S., \& Ayyad, Z. (2011). Fundamental Elements to Produce Sesame Yoghurt from Sesame Milk. American Journal of Applied Sciences, 8(11), 1086-1092.

Almendáriz, C., \& Bolaños, E. (2012). Desarrollo de una bebida fermentada saborizada de soya. Tesis de Ingeniería, 8. Cumbayá, Ecuador: Universidad San Francisco de Quito.

Álvarez, C., \& Cecilia, Y. (2013). Elaboración y caracterización de dos bebidas proteicas, una a base de quinoa malteada y la otra a base de quinua sin maltear (Chenopodium quinoa). Tesis de maestría no publicada, 1-14. Tacna, Perú: Universidad Nacional Jorge Basadre Grihman, Facultad de Ciencias Agropecuarias.

Beuchat, L., \& B, N. (1987). Fermentation of Peanut milk with Lactobacillus bulgaricus and L. acidophilus. Journal of Food Science, 43, 1109-1112.

Bolado, E., \& Acedo, E. (2006). Sugar Catabolism in Bifidobacteria. Revista Salud Pública y Nutrición, 7(4), 104-111.

Brown, A., \& Valiere, A. (2004). Probiotics and medical nutrition therapy. Nutritional Clinical Care, 56-68.

Bucker, E., Mitchell, J., \& Jhonson, G. (2013). Lactic fermentation of peanut milk. Journal of Food Science, 44 (1), 1534-1538.

Chan, L., \& Beuchat, L. (1992). Chemical, physical, and sensory characteristics of peanut milk as affected by processing conditions. Journal of Food Science, 57 (1), 401- 405.

Courtin, P., \& Rul, F. (2003). Interactions between microorganisms in a simple ecosystem: yogurt bacteria as a study model. Diary Science \& Technology, 84, 125-134.

Courtin, P., \& Rul, F. (2003). Interactions between microorganisms in a simple ecosystem: yogurt bacteria as a study model. Diary Science \& Technology, 84, 125-134.

Dong, J., Oh, S., Hyung, K., Mok, C., Hun Kim, S., \& Imm, J. (2005). Characteristics of yogurt-like products prepared from the combination of skim milk and soymilk containing saccharified-rice solution. International Journal of Food Science and Nutrition, 56(1), 23-34.

FAOMHO. (2013). Nutritional Properties. In Quinoa: An ancient crop to contribute to world food security. 
Gill, H., \& Prasad, J. (2008). Probiotics, Immunomodulation, and Health Benefits. Bioactive Components of Milk. Advances in Experimental Medicine and Biology, 606, 423-454.

Gorbach, S. (2000). Probiotics and gastrointestinal health. The American Journal of Gastroenterology, 95(1), S2-S4.

Guinee, T., Fenelon, M., Kelly, P., Kennedy, B., \& Wilkiinson, M. (2000). The effect of total protein, casein:whey protein ratio and fat content on the rheological and syneretic properties of yogurts. Irish Journal of Agriculture and Food Research, 39, 171.

lancu, C., Barbu, V., Nicolau, A., \& Iordachescu, G. (2010). Attempts to obtain a new symbiotic product based on soy milk. Innovative Romanian Food Biotechnology, (7), 21-29.

Ishimoto, E., \& Monteiro, M. (2010). Quinoa (Chenopodium quinoa Willd.) as functional food. Revista Brasileira de Ciências da Saúde, 62-67.

Jiménez, C., Hernández, H., \& Dávila, G. (2003). Production of a yogurt-like product from Lupinus campestris seeds. Journal of the Science of Food and Agriculture, 44, 515522.

Luquet, F. (1993). El yogur. En Leche y productos lácteos. Vaca-Oveja-Cabra (págs. 3953). Zaragoza: Acribia S.A.

Maldonado, P. (2010). Embutidos fortificados con proteína vegetal a base de quinua (Chenopodium quinoa Wild). Tesis de Ingeniería . Quito, Ecuador: Universidad Tecnológica Equinoccial.

Martensson, O., Oste, R., \& Holst, O. (2000). Acid Bacteria in Oat-based Non-diary milk subsitute: Fermentation characteristics and Exopolysaccharide Formation. Center of Chemestry and Chemical Engeneering, 50-62.

Martensson, O., Staaf, J., Duenas, M., Irastorza, A., Oste, R., \& Holst, O. (2002). A fermented, ropy, non-dairy oat product based on the exopolyssaccharide producing strain Pediococcus damnosus. Advances in Food Sciences, 57, 4-11.

Mazón, N., Peralta, E., Rivera, M., Villacré, E., \& Subía, C. (2009). Investigación y desarrollo de granos andinos: chocho y quinoa un aporte a la seguridad y soberanía alimentaria de comunidades del cantón Saquisilí. Cotopaxi, Ecuador: INIAP CORPOINIAPMcKNIGHT.

Moses, O. (2012). Production and Quality Evaluation of Soy-Corn Yoghurt. Advanced Journal of Food Science and Technology, 4(3), 130-134.

Nnam, N. (2003). Nutrient composition and acceptability of vegetable milks made from oilseeds. Journal of Home Economics, 5(1), 57-61.

Opara, C., Ahiazunwo, N., \& Okorie, O. (2013). Production of Soy-Yoghurt by Fermentation of Soymilk with Lactobacillus Isolated from Nunu. International Journal of Science and Engineering Investigations, 2(12), 1-5.

Reddy, N., \& Pierson, M. (1994). Reduction in antinutritional and toxic components in plant foods by fermentation. Food Research International, 28 I-290.

Rojas, W., Pinto, M., \& Soto, J. (2010). Distribución geográfica y variabilidad genética de los granos andinos. Bioversity International Journal, 23, 11-13.

Sánchez, J. (2012). Transformación de datos o cambios de escala. En Introducción al Diseño Experimental (págs. 65-66). Quito: Cámara Ecuatoriana del Libro.

Schrezenmeir, J., \& Vrese, M. (2001). Probiotics, prebiotics, and synbiotics Approaching a definition. The American Journal of Clinical Nutrition, 361-364.

Stanbury, P., Whitake, A., \& Hall, S. (2013). Principles of Fermentation Technology. Oxford: Butterworth Heinemann.

Supavititpatana, P., Indrarini, T., \& Raviyan, P. (2010). Characteristics and Shelf-Life of Cron Milk Yogurt. Journal of Natural Science, 9(1), 133-147.

Torres, M. (2011). La comparación de almidón nativo y modificado de maiz (zea mays) y goma xanthan en el comportamiento reológico de paté de champiñones (agaricus bisporus). Tesis de Ingeniería. Ambato, Ecuador: Universidad Técnica de Ambato.

Vega-Gálvez, A., Vergara, J., Miranda, M., Uribe, E., Puente, L., \& Martinez, E. (2010). . Nutrition facts and functional potential of quinoa (Chenopodium quinoa willd.), an 
ancient Andean grain: a review. Journal of the Science of Food and Agriculture, 25412547.

Witting, E. (2014). Evaluación Sensorial. Una metodología actual para la tecnología de alimentos. Universidad de Chile: http://mazinger.sisib.uchile.cl/repositorio/lb /ciencias_quimicas_y_farmaceuticas/wittinge01/index.html 